\title{
Enzalutamide/Triptorelin Regimen
}

National Cancer Institute

\section{Source}

National Cancer Institute. Enzalutamide/Triptorelin Regimen. NCI Thesaurus. Code C160513.

A regimen consisting of enzalutamide and triptorelin that can be used for the treatment of prostate cancer. 